\title{
How brand loyal shoppers respond to three different brand discontinuation scenarios
}

\author{
Denisa Hebblethwaite,
}

Business Practice, Unitec Institute of Technology, Auckland, New Zealand

Andrew G Parsons,

Department of Marketing, Portsmouth Business School, University of Portsmouth, Portsmouth, UK

Mark T. Spence,

Department of Marketing, Bond University, Gold Coast, Australia

Keywords Brand discontinuation, rebranding, shopper response, switching behaviour, scanner panel data, quasi-experiment 


\begin{abstract}
Purpose - Retailers may respond to a manufacturer discontinuing a brand or product range in three ways: not offering an alternative, thus reducing the assortment size; replacing it with a substitute; or introducing a rebranded product by the same manufacturer, if such an option is available. Herein we study all three scenarios and assess the extent to which total category sales are affected; how these discontinuations affect alternative offerings within the product category; and whether usage levels moderate within category switching behaviour. Shoppers did not have the option of switching stores to acquire the discontinued brand - their preferred brand/product range ceased to exist.
\end{abstract}

Design/methodology/approach - All three studies are quasi-experiments using scanner panel data. The product discontinuations examined are real events that took place within the major supermarket chain in New Zealand.

Findings - In all three scenarios average category sales decreased for the three-month period following the discontinuation. In Study 1 where a preferred brand of milk was discontinued with no replacement overall category sales decreased but competing brands gained sales; introducing a replacement corn chip range (Study 2) successfully captured the spend on the discontinued range, but other brands lost sales; and rebranding a cereal (Study 3) decreased both brand sales and category sales. With the exception of Study 1, near substitute product offerings did not capture a greater proportion of the spend from the discontinued brand compared to less similar substitutes. Expectations were that heavy users would have a greater propensity to shift to near alternatives than would medium/light users, however, none of the studies lend support.

Originality/value - This is the first research effort to use scanner panel data to explore the reactions by brand loyal customers to three different brand discontinuation scenarios initiated by the manufacturer. 


\section{Introduction}

Brand discontinuations are a common feature of the supermarket landscape as national brands continually update to match the market, retailers squeeze brands out given the competition for limited shelf space, and private label and international brands increasingly vie for shoppers' attention. Brands may be discontinued in a number of ways. A temporary discontinuation or out-of-stock situation is often addressed by the shopper through switching stores or purchase deferment (Aastrup \& Kotzab, 2010; Corstjens and Corstjens, 1999; Emmelhainz, Stock and Emmelhainz, 1991; Verbeke, Farris and Thurik, 1998; Sloot, Verhoef, \& Franses, 2005; Yanguni \& El Aoud, 2015). This discontinuation is generally unplanned by the retailer and/or the manufacturer, unless it is a seasonal discontinuation.

With permanent discontinuations the manufacturer or the retailer can initiate them. In the latter case the shopper may have the option to switch stores if accessible competition continues to stock the item and the shopper is willing to make the effort to switch stores, as might be the response to a conflict delisting (Van der Maelen, Breugelmans and Cleeren, 2017). When the manufacturer discontinues a product offering, however, the option of switching stores to acquire it is not available. There are three ways a retailer may respond to a manufacturer discontinuing a brand or product range: not offering an alternative to the discontinued brand, thus reducing the size of the customer's availability set; replacing the brand with a substitute; or introducing a rebranded product by the same manufacturer, if such an option is available. Herein, all three situations are explored.

When considering permanent discontinuations, studies to date have focussed either on store switching behaviour of shoppers in retailer initiated discontinuations (Campo, Gijsbrechts and Nisol, 2004) or switching to in-store substitutes by shoppers when faced with a reduction in assortment - the 'no alternative introduced' scenario. Studies of the latter have 
had mixed results, largely explained by contextual factors such as the categories chosen and the starting size of the assortment (Borle et al., 2005; Iyengar and Lepper, 2000). In Study 1 we consider a frequently purchased, large assortment category (milk) with a manufacturer discontinuation and no alternative introduced. Category sales for necessity items tend to be little affected (Borle et al. 2005); however, the focus here is on how category sales are affected by those loyal to the discontinued brand. Their preferred brand is simply no longer available. How will they respond?

In Study 2 we consider the discontinuation of a nationally known corn chip product range with immediate (overnight) replacement by an internationally branded product range new to the local market. Barring similarity in form, the two ranges share no image overlap. In the discontinuation with immediate replacement case there is no assortment reduction, but the product range that the shopper has invested their loyalty in has ceased to exist. Given the international stature of the replacement product range, a reasonable assumption would be that there would be switching within the category when the shoppers preferred product range is discontinued, but the refreshed product category composition should mitigate any loss in total category sales. What makes this particular study context noteworthy is that there was none of the usual 'new product range' marketing accompanying the introduction, thus enabling us to look solely at replacement effects without the need to tease-out confounding variables such as changes in ad spend and price promotions (Simonson, 1999).

Study 3 considers a different scenario to those above. A marketing tactic available to manufacturers to create a new level of interest and ideally reinvigorate their sales in a stagnant category is through rebranding an existing product. In this case, the manufacturer's name was prominent so much of the associated brand imagery would be expected to transfer from the discontinued brand to the new brand. Little is known, however, about the response to this discontinuation-through-rebranding by shoppers loyal to the discontinued brand. To 
the consumer, the rest of the 'mix' of product attributes (e.g., the brand/firm symbolism, icons and personality) is largely unchanged. Our third study examines the outcome for a brand of cereal rebranded to match a manufacturer's umbrella brand.

This paper is organized as follows. In the next section we share insights regarding what is known about brand discontinuations. We then present three quasi-experiments using scanner panel data to explore the three aforementioned brand/product range discontinuation scenarios. Specifically, we assess the extent to which total category sales are affected; how these discontinuations affect alternative offerings within the product category; and whether usage levels moderate within category switching behaviour. In all cases the sample is restricted to individuals that exhibited a degree of loyalty to the discontinued brand, thus shedding insight into how these customers react to the discontinuation. In light of the findings from these studies, we revisit the assumptions that retailers and manufacturers would expect when implementing brand discontinuations.

\section{Conceptual background}

Numerous studies suggest there is a positive relationship between assortment size and shopper spend (Oppewal and Koelmeijer, 2005; Pizzi and Scarpi, 2013; Reutskaja and Hogarth, 2009; Sela, Berger and Wendy, 2009), but at the margin findings are nuanced. Reducing the assortment size can lead to an increase in sales so long as the cuts are not too deep and the favoured brand is not deleted (Boatwright and Nunes, 2001; Dreze, Hoch and Purk, 1994; Hokelekli et al. 2017). Alternatively, others (Boatwright and Nunes, 2004; Borle et al. 2005; Sloot, Fok and Verhoef, 2006) have found significant category sales losses due to assortment reductions. Gázquez-Abad et al. (2016) found a negative relationship between assortment size and intentions to switch stores to purchase from the category. Permanent assortment reduction studies that resulted in negative sales effects were most commonly a 
result of customers not being able to find their preferred item in the store (Campo and Gijsbrechts, 2005; Campo, Gijsbrechts and Nisol, 2000, 2004; Sloot, Fok and Verhoef, 2006). The positive sales or no sales effects (Dréze, Hoch and Purk, 1994; Broniarczyk, Hoyer and McAlister, 1998; Boatwright and Nunes, 2001) were thought to have occurred because of the decrease in search complexity given the smaller assortments (Iyengar and Lepper, 2000). Decreasing search complexity can attract new buyers into the product category (Sloot, Fok and Verhoef, 2006). An alternative explanation for the equivocal findings is advanced by Borle et al. (2005), who speculated that it was the product categories studied. Product categories that were frequently purchased, such as milk, bread, cereal and soft drinks, were less adversely affected by assortment reductions. We analyse large assortment, frequently purchased categories, namely milk, snack foods and cereal; however, our focus is on the reaction of brand loyal customers to their brand/product range being discontinued.

Retailers often carry out permanent assortment reductions as part of a cost cutting exercise with the low selling stock keeping units delisted from the retailer's product categories (Broniarczyk, Hoyer and McAlister, 1998). However, permanent discontinuations are not always relegated to low selling items. Sloot and Verhoef (2008) and Wiebach and Hildebrandt (2012) focussed on consumers' responses to a brand discontinuation where the delisted brand was not a low selling item. Using a controlled online experiment and an instore shopper survey Sloot and Verhoef (2008) examined the impact of a discontinuation of the consumers' preferred brand on retail sales in 10 product categories. Focusing on the consumers' brand and store switching intentions, they argued that if the brand discontinuation severely hurt sales then the retailer would think twice about threatening the manufacturer with a brand discontinuation. They found that many consumers stay brand loyal and switch stores for their preferred brand, and a small percentage of consumers stop buying at the store 
completely if their preferred brand is delisted. These insights imply a loss of sales at the category level and, in some cases, a loss of the consumer's total shopping basket. Their study also revealed that the main drivers of brand and store switching intentions were brand equity, market share and whether the product was of a hedonic nature (see also Zhang and Krishna, 2007). Discontinuations of brands with high market share or brand equity in hedonic product categories were found to have stronger negative effects on category sales and store choice because consumers were less inclined to switch to another brand. These findings echo those of Van der Maelen et al. (2017) regarding conflict delistings: retailers suffered sales losses when they unilaterally delisted a prominent manufacturer's brands. Key moderators were assortment size, brand equity and necessity versus impulse categories. A large assortment size reduced the loss in sales experienced by the retailer whilst reducing assortment in necessity categories generated the greatest loss for both retailer and manufacturer.

Herein we study three operationally different brand/product range discontinuation scenarios all within large assortment categories. Importantly, the focus is on manufacturerinitiated discontinuations, not temporary discontinuations or discontinuations initiated by the retailer (see Figure 1). Note that in the case of a temporary brand discontinuation the catalyst is typically demand exceeding supply, leading to an out-of-stock event. Customers can then act in one of four ways: defer the purchase, switch stores, switch brands, or stop purchasing. With the exception of the latter, customers are likely to return to normal purchasing once the out-of-stock situation is resolved, and during the out-of-stock situation the retailer may offer an incentive to defer or switch brands temporarily to retain the customer. If the discontinuation is permanent and initiated by the retailer, the customer has the options of switching stores, switching brands or stop purchasing. Again, the retailer is likely to offer an incentive to switch brands or spend on other items within the store. However, in the case of a manufacturer initiated permanent brand discontinuation the customer cannot defer 
purchase or switch stores to acquire the brand elsewhere. Their only options are to switch brands or not purchase the product. Findings regarding overall category sales effects in this situation are limited and equivocal. Our interest is how brand loyal customers react - their preferred brand has simply ceased to exist. Not finding one's preferred brand has been shown to have deleterious consequences on category sales (Campo and Gijsbrechts, 2005; Campo, Gijsbrechts and Nisol, 2000, 2004; Sloot, Fok and Verhoef, 2006). Our overarching hypothesis is therefore:

H1: Discontinuing a preferred brand will result in an overall reduction in product category sales.

"Insert Figure 1 about here"

Wiebach and Hildebrandt (2012) advance context theory to explain customers' within product category switching behaviours to a brand discontinuation. Previous research on context-dependent choices has explored how adding alternatives affects choices (e.g., Simonson, 1989). Wiebach and Hildebrandt (2012) used these insights as a basis to develop hypotheses for a brand discontinuation, the obverse of these scenarios. In two quasiexperiments and an on-line survey all of which elicited students' stated preferences, not real choices, the major finding of their research was that consumers of pizzas, cereals and orange juices tended to substitute with a similar brand rather than switching stores, thus confirming a negative similarity effect. The authors concluded that "[T] he current research reveals that removing "dominated", "similar" or "extreme" alternatives from the shelf affects the choice shares of the remaining brands in a theory-based predictable way" (Wiebach and Hildebrandt 2012, p. 9). Their findings are relevant to this study for two reasons. First, the type of switching response options available to our shoppers are similar to that of a consumer facing a permanent product discontinuation in that they are forced to switch to another brand 
within the product category or to discontinue purchases within the category. In their studies, few respondents indicated that they would switch stores and overall sales were negligibly affected. Second, the negative similarity effect finding provides a theoretical lens from which to hypothesize switching response behaviour by consumers facing a permanent brand discontinuation. Consumers facing a discontinued brand scenario will tend to substitute disproportionately in favour of a brand that has similar attributes (see also Muller and Diels, 2016). We therefore advance:

H2: Discontinuing a preferred brand will have a greater effect on near substitutes than more distant substitutes. Specifically, near substitutes will benefit more from a permanent discontinuation than more distant substitutes.

Based on consumer interviews, Emmelhainz, Stock and Emmaelhainz (1991) found that high volume consumers relative to low volume consumers were more prone to shift allegiances disproportionately to a near substitute. What will light users do? Light users are less attached to the discontinued brand, thus may be more open to variety seeking within the product category. If this were the case there would be a greater propensity to purchase less similar substitutes relative to heavy users. Thus:

H3: The shift to near substitutes will be greater for heavy users compared to medium/light users.

Product assortments are reduced for a variety of reasons (refer to Figure 1). Herein we explore three cases where a brand or product range is discontinued at a national level by the manufacturer. Figure 2 illustrates the three cases studied: (Study 1) do nothing, reduce the choice set, and assess the extent that customers switch to substitute brands; (Study 2) introduce a new brand as a replacement; and (Study 3) accept and stock a rebranded version from the current manufacturer. Each of these options faces difficulties. If nothing is done (1), 
customers who have already determined a preference for the discontinued brand may not switch to a substitute brand, potentially reducing overall basket sales for the retailer. If a new brand is introduced (2) there will be associated marketing costs and it may take time to rebuild the sales levels. It may also be the case that there was a good reason why a substitute was not stocked in the first place, such as not suiting this market; however, we study the responses of customers loyal to the discontinued brand. And, if the manufacturer discontinued because they were rebranding (3), the new branding collateral and attributes may not suit the customers that preferred the original brand. Figure 2 also illustrates the factors hypothesized to affect customers' reactions: the perceived proximity of the substitute(s) in terms of attributes is likely to affect the willingness of customers to switch brands (H2); and, usage level is likely to moderate switching propensity (H3).

Three quasi-experiments follow, starting with the situation where a preferred brand is discontinued by the manufacturer and the retailer does not introduce a new option to replace the delisted brand. Because all three studies use a similar, quasi-experiment methodology, for reasons of parsimony a general overview of the research methodology is presented first.

"Insert Figure 2 about here"

\section{Methodology}

All three studies are quasi-experiments using scanner panel data where manipulations naturally occurred. The brand or product range discontinuations examined in this research are real events that took place within the major supermarket chain in New Zealand. A characteristic of these natural experiments is the non-randomised assignment of subjects to the experimental and control groups. Given the absence of random assignment internal validity could be compromised; however, this is not 
considered a cause for concern due to the large size of the data sets that included all the shoppers that purchased the focal brand nine months prior to its discontinuation. To discount the effect of extraneous variables affecting results that could have occurred during the study horizon, control groups have been included in each of the three studies. The control group comprised shoppers who had purchased from the same product category as the 'experimental group', but who had not purchased the discontinued brand. While we acknowledge that factors other than assortment size affect buyer preferences (Simonson, 1999), if there is no change in the shopping spend of the control group before versus after the discontinuation this provides some assurance that the product category was not unduly affected by extraneous events. Experimentation in natural settings have been used in consumer response to out-ofstock studies (Emmelhainz, Stock, \& Emmelhainz, 1991; Zinn \& Liu, 2001) as well as permanent assortment reduction studies (Boatwright \& Nunes, 2001, 2004; Borle, Boatwright, Kadane, Nunes, \& Galit, 2005; Broniarczyk, Hoyer, \& McAlister, 1998; Dréze, Hoch, \& Purk, 1994; Sloot, Fok, \& Verhoef, 2006; Sloot \& Verhoef, 2008).

The experiments adopt a repeated measures design as the same shoppers' purchases are measured prior to and following the product discontinuation. Scanner panel data has several advantages over survey-based research. First, threats to validity associated with reported purchase intentions and/or actual behaviour are overcome, an important consideration as indicated by an out-of-stock study conducted by Zinn and Liu (2008) that uncovered a considerable difference between intentions and actual behaviour. Second, scanner panel data allows for more accurate tracking and analysis of the individual's responses. The scanner panel data for this research were collected from shoppers' Flybuys loyalty card. Consumers are not required to sign-up for a Flybuys 
card, but this free-to-enrol points-earning loyalty program confers benefits, hence are widely subscribed to.

This research effort investigates the impact of three different brand discontinuation scenarios (Studies 1 to 3, refer to Figure 2) by those loyal to the discontinued brands. Within category choice shifts as a result of the brand discontinuations, measured in terms of average monthly dollar sales, are the response variables. With the assistance of store management, brands within the product category were put into one of three groups (labelled S1 to S3) depending on the similarity in product attributes to the discontinued brand, thus enabling the ability to formally test if discontinuing a brand disproportionately affects near substitutes.

In all three studies analyses are restricted to those individuals that exhibited loyalty to the discontinued brand. Loyalty in this instance is defined as customers that purchased at least three units of the discontinued brand during the nine months prior to discontinuation, and purchased on at least two separate occasions. They also must have purchased the discontinued brand within three months of the final deletion date and must have purchased from the overall category of interest in at least eight of the nine preceding months. These loyal customers were then parsed into heavy, medium and light users depending on purchase amount of the discontinued brand, thus affording the ability to assess the extent, if any, that purchasing level has on within category brand shifts. In all three studies we examine large assortment FMCG food categories: milk (Study 1), snack food (Study 2) and cereal (Study 3).

\section{Study 1}

Data were obtained for purchasers of a brand of milk called Anlene that came in two sizes, 2 litres and 1 litre, both of which were discontinued. The 2 litre version accounted for $81 \%$ of 
Anlene sales. Anlene was a niche milk product with added vitamin D for adults with enhanced calcium needs. The initial data set was of all purchases (953,600 sales transactions) by 701 purchasers of Anlene milk across 47 stores; of these, 455 were subsequently classified as Anlene loyal customers as per the methodology. There was also a control group consisting of 279 shoppers who had purchased milk in the three months preceding the discontinuation but who had not purchased Anlene in the preceding nine-month period. The milk product category excludes broader dairy products such as cream, flavoured milk, and yoghurt.

To assess the extent of switching within category post-deletion, milk products were classified into three types: (S1) similar specialised milk products to Anlene, such as brands enriched with calcium for bone health (e.g., Sun Latte milk); (S2) less similar products, ones with limited health benefit claims such as low fat or organic, but no specific calcium benefit claims (e.g., Anchor Milk Lite); and (S3) non-similar products such as regular or standard milk products with no specific health benefit claims (e.g., Anchor Blue Top). Determination of similarity was made in conjunction with the management responsible for overseeing the category for the supermarket chain. Following the lead taken by Guadagni and Little (1983) and Fader and Hardie (1996), all product items in the defined sub-categories were classified based on key attributes of the discontinued product, notably health benefit claims.

To examine if heavy purchasers of the discontinued brand will demonstrate a greater propensity to switch to a similar substitute than will medium or light purchasers, the 455 shoppers were profiled into three groups based on natural breaks in the histogram of quantities purchased of the discontinued brand: 115 shoppers (25\%) were classified as light purchasers (3-8 units in the preceding nine months); 218 shoppers (48\%) medium purchasers (9-22 units); and 122 shoppers (27\%) heavy purchasers (23-60 units). 


\section{Results}

Of the 455 Anlene buyers, 11 did not purchase milk of any sort in the three months subsequent to the discontinuation, so $97.6 \%$ of shoppers switched within the category. However, for those shoppers the average monthly sales of $\$ 19.30$ across all milk brands from the nine months prior to the discontinuation decreased significantly to average monthly sales of $\$ 16.01$ in the three months subsequent to the discontinuation $(\mathrm{t}[454]=9.30, p<0.001, \mathrm{r}$ $=.84$ ). These figures appear in Table I and support H1. Anlene's sales constituted \$10.27 (53\%) of the $\$ 19.30$ spend. What happened to the "lost" Anlene sales?

"Insert Table I about here"

With respect to near substitutes to the discontinued Anlene brand, that is S1, average monthly sales show a statistically significant decrease from $\$ 13.99$ (including Anlene) prior to the discontinuation to $\$ 8.27$ after the discontinuation, $(\mathrm{t}[454]=16.77, p<0.001, \mathrm{r}=.71$; see Table II). This reduction in sales, however, is substantially less than the foregone Anlene brand sales, thus other S1 category members gained traction. Non-Anlene S1 sales jumped from $\$ 3.73$ to $\$ 8.27$ (122\% increase). Category S2's average monthly sales also showed a significant increase $(\$ 3.32$ to $\$ 5.79 ; \mathrm{t}[454]=-8.72, p<0.001, \mathrm{r}=.74)$. By comparison $\mathrm{S} 3$ 's average monthly sales resulted in no statistically significant difference between the prior average monthly sales of $\$ 1.98$ and the post average monthly sales of $\$ 1.95, \mathrm{t}[454]=.15, p$ $=.88, \mathrm{r}=.72)$. Near substitutes to Anlene therefore gained more than less near substitutes, thus lending support for $\mathrm{H} 2$ despite the overall decline in $\mathrm{S} 1$ category sales. In this case, no replacement brand was offered.

"Insert Table II about here" 
We next consider how buying behaviour is affected by purchasing level by examining how heavy, medium or light purchasers alter their total spend across categories S1 to S3. Prior to the discontinuation, heavy purchasers spent $\$ 18.12(65 \%)$ of their total spend of $\$ 27.78$ on Anlene; after the discontinuation their total spend dropped to $\$ 22.36$. How they reallocated their milk expenditures appears in Figure 3. S1 suffered heavy losses $(\$ 9.85)$, while S2 experienced modest gains (\$4.15). S3 was little affected. This analysis was repeated for medium and light users. The total spend for medium and light users postdiscontinuation was $\$ 15.27$ and $\$ 10.66$, respectively. Medium and light users followed a similar pattern to that of heavy users, albeit of smaller dollar magnitude: reduction in sales in $\mathrm{S} 1$ were greater than were gains in sales to S2 (refer to Figure 3). S3 was little if any affected. H3 is therefore not supported.

"Insert Figure 3 about here"

\section{Control group analysis}

Analysis of the control group showed no significant change in average monthly sales within the milk category three months prior to the discontinuation versus three months after (means $=\$ 26.78$ and $\$ 26.48$, respectively, $\mathrm{t}[278]=.60, p=.55)$, thus providing some support that there were no major extraneous factors affecting milk sales that could have affected the results of the Anlene loyal group.

\section{Discussion}

Findings from this study show that when a manufacturer discontinues a preferred brand total category sales decrease, adversely affecting the retailer. Near substitutes (S1) gained sales, but not sufficient to compensate for the lost Anlene sales. Nevertheless, near-substitute gains exceeded the gain in sales to S2; S3 was unaffected. Some consumers moved away from 
brands with specialized health claims to low fat options. This pattern of behaviour, overall sales losses in S1 (despite significant increases in near-substitute sales), smaller but positive gains in S2, was realized regardless of usage level. The magnitude of change mirrored usage levels: heavy users had bigger swings than did medium/light users, not surprising given their bigger dollar spend. While specialized milk products lost share overall, competitors to Anlene experienced gains, albeit not at levels matching the foregone Anlene sales. Thus, for manufacturers still in the market the shift in market shares did not simply benefit direct competitors, broader category members benefited as well.

Given that overall category sales fell, it appears to be in the retailers' interests to find a replacement brand rather than assume the remaining brands will absorb the market share of the discontinued brand. In Study 2 we consider the scenario where an immediate replacement is introduced by the retailer.

\section{Study 2}

Study 2 explores the ramification of discontinuing a popular corn chip product range and replacing it with an internationally available range that, barring similarity in form, shares no image overlap. The Bluebird Corn Chip (CC) range consisting of three flavours and 4 SKUs was discontinued, but immediately replaced with the Doritos range of corn chips. The replacement range was larger: 5 flavours and 10 SKUs. The most popular variety within the Bluebird CC range was the Tasty Cheese $190 \mathrm{~g}$ variant, accounting for $64 \%$ of Bluebird CC sales. Doritos rolled-out two near substitutes, Doritos Cheese Supreme 170g and Doritos Nacho Cheese 170g. Through a series of acquisitions the focal discontinued range, Bluebird Corn Chips, was ultimately acquired by Pepsico, the producer of the replacement Doritos range. However, in neither case was the parent company's name prominently displayed on the respective packages. A post hoc survey $(n=48)$ found that only $6.3 \%$ of respondents 
could identify the manufacturer of the Bluebird range, and only $12.5 \%$ could correctly identify that Doritos was produced by Pepsico. Thus, for most consumers these product ranges could very well be produced by different manufacturers.

Analogous to Study 1, participants had to exhibit loyalty to the Bluebird CC range. These 403 individuals were profiled into three groups based on units purchased: light users purchased 3 to 4 units $(n=168,42 \%)$; moderate users between 5 to 7 units $(n=124,31 \%)$; and heavy users $(\mathrm{n}=111,27 \%)$ purchased between 8 and 28 units. One hundred ninety shoppers were in the control group. With input from store management, product subcategories were determined, and defined as corn chips (S1), non-corn chips (e..g., potato chips: S2) and non-chip savoury snacks (S3).

Following the analyses used in Study 1, a frequency analysis to determine how many shoppers ceased purchasing within the category post-discontinuation was conducted. The results show that of the 403 shoppers who purchased from the Bluebird CC range before the discontinuation, 10 shoppers did not purchase from the snack category in the three months following the product discontinuation, thus $97.5 \%$ of shoppers switched within the category. For many, snack foods are not necessity items as is milk, but a similar percentage of brand loyal customers ceased purchasing within the product category as was the case in Study 1.

A paired samples t-test was conducted to compare mean average monthly sales nine months prior versus three months following the discontinuation. On average, Bluebird CC's shoppers' monthly spend in the total snack category showed a statistically significant decrease from $\$ 25.48$ to $\$ 23.48$ after the discontinuation $(\mathrm{t}[402]=2.99, p=$ $.003, \mathrm{r}=.72$ ), thus $\mathrm{H} 1$ is supported.

We then examined the extent to which the Dorito's range replaced sales of the discontinued Bluebird CC range. The average monthly sales of \$2.56 for the Doritos' 
brands for the three month period after the discontinuation of the Bluebird CC range is not significantly different than the average monthly sales of $\$ 2.59$ for Bluebird's CC $(\mathrm{t}[402]=0.16, p=.87, \mathrm{r}=.32)$; thus, it can be argued that Doritos successfully replaced the Bluebird range. What happened to the sales of other brands?

The effects on categories S1 to S3 pre- versus post-discontinuation were therefore assessed. These results appear in Table III. The average monthly sales within S1 including the Bluebird/Doritos range of brands decreased significantly from $\$ 4.44$ to $\$ 3.99(\mathrm{t}(402)=2.14, p=.031, \mathrm{r}=.52)$. Following a similar trend, the average monthly sales for category S2, which consists of non-corn chips, resulted in a statistically significant decrease from $\$ 16.25$ prior to the discontinuation to $\$ 14.99$ after the discontinuation, $(\mathrm{t}(402)=2.43, p=.02, \mathrm{r}=.73)$. There was no significant difference in the average monthly sales for S3, which consisted of non-chip snacks. Average monthly sales prior to the discontinuation were $\$ 4.78$ versus $\$ 4.50$ after the discontinuation ( $\mathrm{t}$ $(402)=1.41, p=.16, \mathrm{r}=.70)$. Thus, the Doritos range successfully replaced the sales of the discontinued Bluebird CC range, but the remaining S1 and S2 category sales were negatively affected, resulting in an overall reduction of snack food sales. When viewed as a percentage of sales, there was more damage to S1 (sales off 11.2\%) than to S2 (off 8.4\%), thus $\mathrm{H} 2$ is not supported.

"Insert Table III about here"

Prior to the discontinuation of the Bluebird CC range, heavy purchasers spent $\$ 6.49$ of their total average monthly spend of $\$ 33.27$ on Bluebird/S1 brands; after the discontinuation their spend dropped to $\$ 30.32$ and Doritos/S1 sales comprised $\$ 5.29$ of that, a significant decrease $(\mathrm{t}[110]=2.097, p=.038, \mathrm{r}=.39)$. For medium users, the average spend figures pre- versus post-discontinuation were $\$ 23.38$ and $\$ 21.43$, respectively. Like heavy 
users, there was a significant drop from Bluebird/S1 average monthly sales to Doritos/S1 (means $\$ 4.07$ and $\$ 3.44$, respectively; $\mathrm{t}[123]=2.22, p=.028, \mathrm{r}=.525$ ). For light users average monthly change went from $\$ 21.87$ to $\$ 20.48$. There was no significant change from Bluebird/S1 sales to Doritos/S1 (means are $\$ 3.35$ and $\$ 3.26$, respectively; $p=.70$ ). Thus, light users were less likely to defect from near substitutes (S1) than were heavy users, which contradicts H3. While their purchases decreased overall, variety seeking occurred within S1, mitigating sales losses.

How the reduction in sales for each of the three usage levels were dispersed across S1 to S3 appears in Figure 4. As is apparent, most of the reduction across all three purchasing levels was in category S2, an outcome opposite to that of Study 1. However, it is important to note that expenditures in S2 (non-corn chip brands, mostly potato chip brands) exceeded sales of corn chips both pre- and post-discontinuation. Nevertheless, removing the preferred corn chip brand had the most severe dollar impact on S2 category members.

"Insert Figure 4 about here"

\section{Control group analysis}

The control group consisted of 190 shoppers who had purchased from the snack category, but had not purchased from the Bluebird CC range. There was no significant difference in the average monthly spend in the snack category prior to the discontinuation (\$32.04) and post discontinuation (\$30.11) of the Bluebird CC range ( $t$ $(189)=1.28, p=.20)$. These results suggest that no major extraneous shocks affected the snack food category during the study period, hence increases the veracity of the conclusions reached regarding the ramifications of replacing the Bluebird range on loyal customers.

\section{Discussion}


Sales of the discontinued Bluebird CC range were replaced by sales of the introduced Doritos range. Nevertheless, overall snack food category sales declined by nearly $8 \%$. Corn chips comprised a relatively small portion of total snack category sales, yet there was a detrimental spill-over effect on overall snack sales for those loyal to the Bluebird range. The largest decline was in S2 category sales, although sales losses occurred in S1 and S3 as well. Findings show that near substitutes (S1) suffered slightly larger losses - in percentage terms - than more distant alternatives (S2), and that light users were more likely to variety seek within S1 than were heavy/medium users. Unlike heavy/medium users, there was no significant decline in sales between Bluebird/S1 sales and Doritos/S1 sales for light users. Overall, average monthly sales fell \$2.95 (9.7\%) for heavy users versus $\$ 1.39$ (6.8\%) for light users. It can be argued that the replacement Doritos range was larger (10 SKUs versus 4 SKUs), thus the already large snack food category became larger. Increasing search complexity could explain some of the reduction in overall sales (Iyengar and Lepper, 2000).

Study 2 examined the case where a preferred product range was immediately replaced by an alternative range that consumers were unaware came from the same parent company. From the consumer's perspective there would be little if any image overlap between the discontinued product range and the replacement range. In the next study a brand is discontinued but replaced with a near alternative clearly labelled as produced by the same manufacturer, thus maximizing brand image overlap.

\section{Study 3}

One tool in a manufacturer's marketing mix tool box to create a new level of interest and reinvigorate sales is through rebranding a tired product. A brand is a name, term, symbol, design, or combination of these that forms the essence of the brand concept, and is important to consumers because it acts as a tool to identify the product, associate perceptions of quality 
and value, and reduce uncertainty and risk (Aaker, 2009). Because existing brands have an established meaning and identity for the consumer it can be cost effective for manufacturers desiring to reinvigorate sales to change the brand name as these brand meanings may transfer to the new brand name. Changing the brand name can also provide opportunities to generate new associations and meanings that may not have existed in the original brand name. The new brand name may also attract new customer segments (Aaker, 2009). Little is known, however, about the response to this discontinuation through rebranding by shoppers loyal to the discontinued brand. There is no assortment reduction, but the brand that the shopper has invested their loyalty in has ceased to exist. In Study 3 a near identical substitute clearly labelled as produced by the same manufacturer was introduced. Will brand loyal customers stay loyal to the manufacturer?

Kellogg's Cocoa Crispix (340 gm box) was discontinued and replaced with a rebranded version of the same product called Kellogg's Coco Pops Chex (340 gm box). Preand post-rebranding the manufacturer's identity, Kellogg's, was prominent. The initial data set was of all purchases made $(1,871,671$ sales transactions) by 852 purchasers of Kellogg's Cocoa Crispix across 48 stores. Consistent with the two previous studies participants must have exhibited loyalty to the Cocoa Crispix brand. This left 540 shoppers that were profiled into three groups to reflect purchasing behaviour: 140 shoppers (26\%) were classified as light purchasers (3-4 units in the preceding nine months); 245 (45\%) medium purchasers (5-10 units); and 155 (29\%) heavy purchasers (11-31 units). There is also a control group of 228 shoppers who had purchased cereal in the three months preceding the discontinuation, but who had not purchased Kellogg's Cocoa Crispix in the preceding nine month period.

As before, to assess category switching behaviour the cereal category was broken into three categories, S1 to S3. Thus, for example, S1 included chocolate flavoured cereals such 
as Hubbards Big Bugs 'N Mud; S2 included non-chocolate sweetened cereals such as Kellogg's Fruit Loops; and S3, less sweetened, more adult-oriented cereals such as Special $\mathrm{K}$.

\section{Results}

A frequency analysis of the three-month period following the discontinuation shows that $97.6 \%$ (527) of the 540 shoppers substituted within the cereal category and only $2.4 \%$ (13) stopped purchasing, so switching within the category is the dominant response. This drop-out rate off $2.4 \%$ is consistent with both Study 1 and 2 .

A paired-samples t-test of the average monthly spend for all cereals from the period nine-months prior to the discontinuation compared with the period three-months subsequent shows that Kellogg's Cocoa Crispix shoppers' monthly spend decreased significantly from $\$ 27.82(\mathrm{SD}=16.83)$ to $\$ 25.51(\mathrm{SD}=18.89 ; \mathrm{t}[539]=4.64, p<0.001, \mathrm{r}=.80)$. Thus, overall cereal sales decreased, supporting H1.

Looking specifically at whether customers of the discontinued Kellogg's Cocoa Crispix switched to the replacement brand, Kellogg's Coco Pops Chex, a paired t-test comparing the average monthly sales for each shows that there is a significant decrease from a $\$ 4.37(\mathrm{SD}=2.95)$ spend on the discontinued brand to $\$ 2.38(\mathrm{SD}=3.94)$ on the new brand $(\mathrm{t}[539]=11.74, p<0.001, \mathrm{r}=.38)$. It is reasonable to assume this was not the outcome desired by Kellogg's. It is important to note the price had not changed. There was, however, a small but significant increase in sales of other Kellogg's flavoured cereals (means $=\$ 1.83$ and $\$ 2.23$, respectively, $\mathrm{t}[539]=-2.93, p=.004, \mathrm{r}=.49$ ), but not sufficient to compensate for the loss due to rebranding.

Next, we determined where shoppers of the discontinued brand switched. Table IV provides the paired t-test results. Including the two focal brands, Cocoa Crispix and its replacement, Coco Pops Chex, there was a statistically significant decrease in sales in S1 
brands $(\mathrm{t}[539]=7.70, p<.001, \mathrm{r}=.64)$, no difference in sales of $\mathrm{S} 2$ brands $(p=.13, \mathrm{r}=.75)$, and a statistically significant reduction in $\mathrm{S} 3$ sales $(\mathrm{t}[539]=2.45, p=.02, \mathrm{r}=.79)$. Thus, overall sales declined and this is largely attributable to the weak performance of the replacement brand and a reduction in purchases of dissimilar alternatives (S3). H2 is therefore not supported.

"Insert Table IV about here"

Next, we consider how usage level affects switching across the three categories. Studies 1 and 2 have already revealed that $\mathrm{S} 1$ suffers losses, and that the size of the losses mirrors usage levels. Here, the largest reduction in sales was again in S1, and this was true for heavy, medium and light users. S2 showed small gains, while S3 also suffered losses. The patterns by usage level are similar for S1-S3, but differ in magnitude. These data appear in Figure 5. H3 is not supported.

"Insert Figure 5 about here"

\section{Control group analysis}

To check that no major extraneous shock affected the changes observed, a control group of 228 customers of cereal (but not the discontinued brand) was examined regarding sales in the cereal category for the 3-months prior to the discontinuation and for the 3-months following the discontinuation. There was no significant difference $(\mathrm{t}[227]=1.84 ; p=.91)$ in sales between the two periods. 


\section{Discussion}

Study 3 considers the case of a manufacturer discontinuing a brand and replacing it with an easily recognizable near substitute, thus brand associations should transfer to the new brand. Yet, sales of the replacement product were significantly lower for those loyal to the discontinued delisted brand. The manufacturer did experience small gains for two other brands in their flavoured cereal range, Coco pops $450 \mathrm{~g}$ and $735 \mathrm{~g}$, but overall suffered losses. Category S2 exhibited small gains for all usage levels suggesting that the removal of the preferred brand encouraged some bounce into less similar but still high sugar cereals (S2), but not distant brands (S3). S3 suffered small losses.

\section{General discussion and conclusion}

How consumers react to brand discontinuations has, to date, had mixed results. The balance of studies suggest that permanent assortment reductions result in a reduction in overall sales (Campo and Gijsbrechts, 2005; Campo, Gijsbrechts and Nisol, 2000, 2004; Sloot, Fok and Verhoef, 2006), but others have found the effect on sales to be nil or positive (Dréze, Hoch and Purk, 1994; Broniarczyk, Hoyer and McAlister, 1998; Boatwright and Nunes, 2001). Our focus was on how brand loyal customers responded to three different manufacturer initiated discontinuation scenarios (refer to Figure 2), hence there was not the opportunity to defer purchase or to acquire their preferred brand at an alternative store.

\section{Theoretical contribution}

In a series of studies involving stated, not revealed, preferences, Wiebach and Hildebrandt (2012,p. 9) found support for a negative similarity effect, concluding that a discontinued brand would disproportionately and positively affect near substitutes, leading the authors to recommend "retailers to always offer a similar alternative to keep customers in the store". In all three studies sales within S1 declined significantly, although in the no replacement scenario (Study 1) near substitutes experienced sales gains but not to the level of the 
discontinued brand. Sales of the Doritos range did successfully replace the sales of the Bluebird corn chip range, but sales of the other category members fell (Study 2). In Study 3, sales of the Kellogg's replacement brand took the brunt of the S1 sales decline. This latter finding suggests that the rebranding failed to capture the imagination of the existing shoppers and is a warning to manufacturers that if contemplating a rebranding they risk losing cache with loyal customers.

In Study 1 less near competitors, those with limited health benefit claims such as 'low fat' (category S2), experienced significant gains. This may be attributable to shoppers prior to the discontinuation purchasing out of habit. Habitual purchase is abruptly stopped with a discontinuation. Faced with a catalyst for change may have encouraged shoppers to switch to choices with more limited health claims because they failed to appreciate the benefits from the original brand. In Study 2 there was a significant, negative spill-over effect on S2. In Study 3, S2 experienced a small but significant increase. The effect on S3 was nil (Study 1) to modestly negative (Studies 2 and 3). All three studies, therefore, sound warnings to retailers and manufacturers that shoppers will not simply shift to near substitutes in the case of a discontinuation, rather sales across all categories may be negatively affected.

Usage level has been advanced as a moderator affecting consumers' reactions to brand discontinuations (Emmelhainz, Stock and EmmelHainz, 1991). Expectations were that heavy users would have a greater propensity to shift to near alternatives than would medium/light users, the argument being that the latter would be more open to variety seeking - they were, after all, less committed to the focal brand in the first place. None of the studies provided support for this hypothesis. A perusal of Figures 3 to 5 shows that switching patterns by usage level are remarkably similar, but differ in magnitude: heavy users exhibit larger swings than medium/light users. Interestingly, the underlying stories across the studies differ. While it was previously noted that overall sales of the Doritos range successfully 
captured the discontinued Bluebird range, this was not true for heavy users: Doritos sales fell short of the Bluebird range, but this decline was offset by small increases in purchases by medium and light users. Loyal, heavy users appear to be more reluctant to try a new offering than do medium and light users. In Study 3, Kellogg's replacement brand fared badly across all usage levels. In short, these studies show that usage levels do not have the impact suggested by previous research. Heavy use does not necessarily translate into brand loyalty, and for the retailer does not even translate into category loyalty.

\section{Practical contribution}

In all three studies total retail sales declined significantly, not only for the retailer, but in the case of Study 3 for the manufacturer as well. Managerially this has significant implications. If a brand or product range is in a mature or declining phase of its lifecycle a typical response is to try and rejuvenate it through rebranding or other changes. Our results suggest this is a poor choice, and that it is better to leave the brand in situ. This study has therefore provided further confirmation that a rebranding approach to brand discontinuation is a risky option for a manufacturer (Collange, 2008).

Brands, particularly in the FMCG market, are facing an increasingly fragmented shopper base with eroding loyalty. Retailers and manufacturers make assortment reduction decisions all the time. Prior studies of related concepts (such as out-of-stock) have provided mixed results and done little to help in this decision making (but see Hokelekli et al. 2017 concerning private labels and Van der Maelen et al. 2017 regarding conflict delistings). Branding related discussions tend toward suggesting that rejuvenation through rebranding or replacement brands would revitalise a product category, but this study shows the opposite occurs. This study showed that not only was the rebranded item negatively affected in terms of sales, but that the entire category suffered negative consequences. Prior studies that have used out-of-stock as a means of studying brand switching or relied on stated preferences have 
not captured this finding. This new knowledge is also supported by the more limited study of private labels by Ruiz-Real, Gazquez-Abad, Esteban-Millat, and Martinez-Lopez (2017) who discuss how retailers who have abandoned national brands in favour of private labels have in some cases had to return the national brands as the anticipated switching did not occur.

\section{Limitations}

All three studies used natural quasi-experiments, capturing revealed behaviour as opposed to stated preferences. The three scenarios studied paint a picture of how a retailer may respond to a manufacturer-initiated brand/product range discontinuation: not offering an alternative, thus reducing the assortment size; replacing it with a substitute; or introducing a rebranded product by the same manufacturer, if such an option is available. Despite these different retailer responses, all three scenarios share common characteristics: all focus on the reaction of brand loyal customers to the discontinuation; all involve large assortment FMCGs; and customers could not acquire the discontinued brand/product range elsewhere. We accept that factors other than assortment size affect buyer preferences, such as alterations to product category presentation and marketing mix actions like sales promotions (Simonson, 1999). It should be assumed that across the 12-month data collection horizon such 'adjustments within the product category' took place. But, the view examined here is at an aggregate level - what happens to sales at the total category level? Clearly, this is of import to retailers and, in Study 3 , the manufacturer. Although the control group analyses were at a course level, none indicated there were changes in consumption levels by those that did not exhibit loyalty to the discontinued brand, providing some assurance that nothing extraordinary happened within the product categories studied. Thus, different though the scenarios are, collectively the findings herein share insights that do not bode well for the retailer: in all three scenarios sales declined. Across all three studies about $2.4 \%$ of brand loyal customers discontinued purchasing within the category of interest. It is possible that the product range/brand 
introduced in Studies 2 and 3 were successful at attracting new customers. For pragmatic reasons data collection post discontinuation was limited to three months. Prior research on permanent assortment reductions has shown that long-term sales declines can be milder than short-term reactions (Sloot, Fok and Verhoef, 2006). Long-term effects could therefore differ from the findings herein.

In sum, brand discontinuations can have a much greater adverse impact than previously anticipated and both manufacturers and retailers must be not only aware of this, but have marketing efforts in place to counter negative consequences. 


\section{References}

Aaker, D. A. (2009), Managing brand equity, NY: Simon \& Schuster.

Aastrup, J., \& Kotzab, H. (2010), "Forty years of out-of-stock research - and shelves are still empty", The International Review of Retail, Distribution and Consumer Research, Vol. 20, No. 1, pp. 147-164.

Boatwright, P., and Nunes, J. C. (2001), "Reducing assortment: An attribute-based approach," Journal of Marketing, Vol. 65, No. 3, pp. 50-63.

Boatwright, P., and Nunes, J. C. (2004), Correction note for "Reducing assortment: An attribute-based approach," Journal of Marketing, Vol. 68, No. 3.

Borle, S., Boatwright, P., Kadane, J. B., Nunes, J. C., and Galit, S. (2005), "The effect of product assortment changes on customer retention," Marketing Science, Vol. 24, No. 4, pp. $612-622$

Broniarczyk, S. M., Hoyer, W. D., and McAlister, L. (1998), "Consumers' perceptions of the assortment offered in a grocery category: The impact of item reduction," Journal of Marketing Research, Vol. 35, No. 2, pp. 166-176.

Campo, K., and Gijsbrechts, E. (2005), "Retail assortment, shelf and stockout management: issues, interplay and future challenges," Applied Stochastic Models in Business and Industry, Vol. 21, Nos. 4/5, pp. 383-392.

Campo, K., Gijsbrechts, E., and Nisol, P. (2000), "Towards understanding consumer response to stock-outs," Journal of Retailing, Vol. 76, No. 2, pp. 219 - 242.

Campo, K., Gijsbrechts, E., and Nisol, P. (2003), "The impact of retailer stockouts on whether, how much, and what to buy," International Journal of Research in Marketing, Vol. 20, No. 3, pp. 273-286. 
Campo, K., Gijsbrechts, E., and Nisol, P. (2004), "Dynamics in consumer response to product unavailability: do stock-out reactions signal response to permanent assortment reductions?" Journal of Business Research, Vol. 57, No. 8, pp. 834-843.

Collange, V. (2008), “L'impact de la substitution de marques sur l'évaluation et l'intention d'achat du produit," Recherche et Applications en Marketing, Vol. 23, pp. 1-17.

Corstjens, J. and Corstjens, M. (1999), Store wars: The battle for mindspace and shelfspace, NY: John Wiley \& Sons.

Diels, J. L., Wiebach, N., \& Hildebrandt, L. (2013), “The impact of promotions on consumer choices and preferences in out-of-stock situations", Journal of Retailing and Consumer Services, Vol. 20, No. 6, pp. 587-598. doi: http://dx.doi.org/10.1016/j.jretconser.2013.04.009

Dréze, X., Hoch, S. J., and Purk, M. E. (1994), "Shelf management and space elasticity," Journal of Retailing, Vol. 70, No. 4, pp. 301-326.

Emmelhainz, M. A., Stock, J. R., and Emmelhainz, L. W. (1991), "Guest commentary: Consumer responses to retail stock-outs," Journal of Retailing, Vol. 67, No. 2, summer, pp. 138-147.

Fader, P. S., and Hardie, B. G. S. (1996), "Modeling consumer choice among SKUs," Journal of Marketing Research, Vol. 33, No. 4, pp. 442-452.

Gázquez-Abad, J. C., Martínez-López, F. J., Esteban-Millat, I., Mondéjar-Jiménez, J. A., \& Rejón-Guardia, F. (2016), "How Delisting All National Brands in a Given Assortment Impacts on Consumers' Store Switching Intentions", in M. W. Obal, N. Krey \& C. Bushardt (Eds.), Let's Get Engaged! Crossing the Threshold of Marketing's Engagement Era: Proceedings of the 2014 Academy of Marketing Science (AMS) Annual Conference (pp. 115-116). Cham: Springer International Publishing. doi:10.1007/978-3-319-11815-4_39 
Guadagni, P. M., and Little, J. D. C. (1983), "A logit model of brand choice calibrated on scanner data," Marketing Science, Vol. 2 (Summer), pp. 203-238.

Hokelekli, G., Lamey, L., and Verboven, F. (2017), "Private label line proliferation and private label tier pricing: a new dimension of competition between private labels and national brands", Journal of Retailing and Consumer Services, Vol. 36, pp. 39-52.

Horsky, D. and Swyngedouw, P. (1987), "Does it pay to change your company's name? A stock market perspective," Marketing Science, Vol. 6, No. 4, pp. 320-335.

Iyengar, S. S., and Lepper, M. R. (2000), "When choice is demotivating: Can one desire too much of a good thing?" Journal of Personality and Social Psychology, Vol. 79, No. 6, pp. 995-1006.

Muller, H., \& Diels, J. L. (2016), "Reversing the similarity effect in stock-outs: A new look at a renowned phenomenon in consumers' brand switching behaviour", Psychology and Marketing, Vol. 33, No. 1, pp. 48-59.

Oppewal, H., \& Koelmeijer, K. (2005), "More choice is better: Effects of assortment size and compositions on assortment evaluation", International Journal of Research in Marketing, Vol. 22, No. 1, pp. 45-61.

Pizzi, G., \& Scarpi, D. (2013), “When Out-of-Stock Products DO Backfire: Managing Disclosure Time and Justification Wording, Journal of Retailing, Vol. 89, No. 3, pp. 352-359. doi: http://dx.doi.org/10.1016/j.jretai.2012.12.003 
Reutskaja, E., \& Hogarth, R. M. (2009), "Satisfaction in choice as a function of the number of alternatives: When goods satiate", Psychology and Marketing, Vol. 26, No.3, pp. 197-203.

Ruiz-Real, J.L., Gazquez-Abad, J.C., Esteban-Millat, I., and Martinez-Lopez, F.J. (2017), "Betting exclusively for private labels: could it have negative consequences for retailers?", Spanish Journal of Marketing - ESIC, http://dx.doi.org/10.1016/j.sjme.2016.12.004

Sela, A., Berger, J., \& Wendy, L. (2009), "Variety, vice and virtue: How assortment size influences option choice", Journal of Consumer Research, Vol. 35, No 6, pp. 941-951.

Simonson, I. (1989), "Choice based on reasons: the case of attraction and compromise effects," Journal of Consumer Research, Vol. 16, No. 2, pp. 158-174.

Simonson, I. (1999), “The effect of product assortment on buyer preferences", Journal of Retailing, Vol. 75, No. 3, pp. 347-370.

Sloot, L.M., Fok, D., and Verhoef, P. C. (2006), "The short- and long-term impact of an assortment reduction on category sales," Journal of Marketing Research, Vol. 43, No. 4, pp. $536-548$

Sloot, L. M., and Verhoef, P. C. (2008), “The impact of brand delisting on store switching and brand switching intentions," Journal of Retailing, Vol. 84, No. 3, pp. 281-296.

Van der Maelen, S., Breugelmans, E., \& Cleeren, K. (2017), “The Clash of the Titans: On Retailer and Manufacturer Vulnerability in Conflict Delistings", Journal of Marketing, Vol. 81, No. 1, pp. 118-135. doi: 10.1509/jm.15.0282

Verbeke, W., Farris, P. and Thurik, R. (1998), "Consumer response to the preferred brand out-of-stock situation," European Journal of Marketing, Vol. 32, Nos. 11/12, pp. 936-1028. 
Verhoef, P. C., \& Sloot, L., M. (2010), “Out-of-stock: Reactions, antecedents, management solutions, and a future perspective”, in M. Krafft \& M. K. Mantrala (Eds.), Retailing in the 21st Century. Berlin: Springer.

Wiebach, N., and Hildebrandt, L. (2012), “Explaining customers' switching patterns to brand delisting," Journal of Retailing and Consumer Services, Vol. 19, pp. 1-10.

Yanguni, W., \& El Aoud, N. (2015), "Consumer behaviour and the anticipation of a total stockout for a food product: proposing and validating a theoretical model", The International Review of Retail, Distribution and Consumer Research, Vol. 25, No. 2, pp. 181-203.

Zhang, J., and Krishna, A. (2007), "Brand-level effects of stockkeeping unit reductions," Journal of Marketing Research, Vol. 44, No. 4, pp. 545-559.

Zinn, W., and Liu, P. C. (2001), "Consumer response to retail stockouts," Journal of Business Logistics, Vol. 22, No. 1, pp. 49-71.

Zinn, W., \& Liu, P. C. (2008). A comparison of actual and intended consumer behaviour in response to retail stockouts. Journal of Business Logistics, Vol. 29, No. 2, pp. 141-159. 
Table I.

Paired samples statistics for total category spend on milk products

\begin{tabular}{|l|l|l|r|r|}
\hline \multicolumn{5}{|c|}{ Paired Samples Statistics } \\
\hline Variables & Mean & N & Std. Deviation & $\begin{array}{l}\text { Std. Error } \\
\text { Mean }\end{array}$ \\
\hline Avg. monthly sales 9 months prior & $\$ 19.30^{*}$ & 455 & 13.29 & 0.62 \\
\hline Avg. monthly sales 3 months after & $\$ 16.01$ & 455 & 13.02 & 0.61 \\
\hline
\end{tabular}

* All figures are in New Zealand dollars.

\begin{tabular}{|l|l|l|l|l|}
\hline & Mean & $\begin{array}{l}\text { Std. } \\
\text { Dev. }\end{array}$ & t & $\begin{array}{l}\mathbf{2}- \\
\text { tailed } \\
\text { sig. }\end{array}$ \\
\hline $\begin{array}{l}\text { Avg. monthly sales 9 } \\
\text { months prior - Avg. } \\
\text { monthly sales 3m after }\end{array}$ & 3.29 & 7.55 & 9.30 & 0.00 \\
\hline
\end{tabular}


Table II.

Paired samples statistics by sub-category, pre- versus post-discontinuation (milk)

\begin{tabular}{|l|l|l|l|r|r|}
\hline \multicolumn{2}{|l|}{ Variables } & Mean & N & $\begin{array}{l}\text { Std. } \\
\text { Deviation }\end{array}$ & $\begin{array}{l}\text { Std. Error } \\
\text { Mean }\end{array}$ \\
\hline S1 * & $\begin{array}{l}\text { avg. monthly sales 9 months } \\
\text { prior }\end{array}$ & 13.99 & 455 & 9.48 & 0.44 \\
\cline { 2 - 6 } & $\begin{array}{l}\text { avg. monthly sales 3months } \\
\text { after }\end{array}$ & 8.27 & 455 & 9.61 & 0.45 \\
\hline S2 & $\begin{array}{l}\text { avg. monthly sales 9 months } \\
\text { prior }\end{array}$ & 3.32 & 455 & 7.11 & 0.33 \\
\cline { 2 - 6 } & $\begin{array}{l}\text { avg. monthly sales 3 months } \\
\text { after }\end{array}$ & 5.79 & 455 & 8.87 & 0.42 \\
\hline S3 & $\begin{array}{l}\text { avg. monthly sales 9 months } \\
\text { prior }\end{array}$ & 1.98 & 455 & 5.44 & 0.25 \\
\cline { 2 - 6 } & $\begin{array}{l}\text { avg. monthly sales 3 months } \\
\text { after }\end{array}$ & 1.95 & 455 & 4.56 & 0.21 \\
\hline
\end{tabular}

* S1 figures include Anlene sales of \$10.27 nine months prior to discontinuation.

\begin{tabular}{|l|l|l|l|l|}
\hline & Mean & $\begin{array}{l}\text { Std. } \\
\text { Dev. }\end{array}$ & t & $\begin{array}{l}\text { 2 - tailed } \\
\text { sig. }\end{array}$ \\
\hline $\begin{array}{l}\text { (S1) avg. monthly } \\
\text { sales 9 months } \\
\text { prior - (S1) avg. } \\
\text { monthly sales 3 } \\
\text { months after }\end{array}$ & 5.73 & 7.28 & 16.77 & 0.00 \\
\hline $\begin{array}{l}\text { (S2) avg. monthly } \\
\text { sales 9 months } \\
\text { prior - (S2) avg. } \\
\text { monthly sales 3 } \\
\text { months after }\end{array}$ & -2.46 & 6.02 & -8.72 & 0.00 \\
\hline $\begin{array}{l}\text { (S3) avg. monthly } \\
\text { sales 9 months } \\
\text { prior - (S3) avg. } \\
\text { monthly sales 3 } \\
\text { months after }\end{array}$ & 0.03 & 3.80 & 0.15 & 0.88 \\
\hline
\end{tabular}


Table III.

Paired samples statistics by sub-category, pre- versus post-discontinuation (snack food)

\begin{tabular}{|l|l|r|r|r|r|}
\hline \multicolumn{2}{|c|}{ Variables } & & & \multicolumn{1}{|c|}{$\begin{array}{c}\text { Std. } \\
\text { Dev. }\end{array}$} & $\begin{array}{c}\text { Std. Error } \\
\text { Mean }\end{array}$ \\
\hline \multirow{2}{*}{ S1* } & Avg. monthly sales 9m prior & 4.44 & 403 & 3.27 & 0.16 \\
\cline { 2 - 6 } & Avg. monthly sales 3m after & 3.99 & 403 & 4.77 & 0.24 \\
\hline \multirow{2}{*}{ S2 } & Avg. monthly sales 9m prior & 16.25 & 403 & 14.14 & 0.70 \\
\cline { 2 - 6 } & Avg. monthly sales 3m after & 14.99 & 403 & 14.05 & 0.70 \\
\hline \multirow{2}{*}{ S3 } & Avg. monthly sales 9m prior & 4.78 & 403 & 4.87 & 0.24 \\
\cline { 2 - 6 } & Avg. monthly sales 3m after & 4.50 & 403 & 5.40 & 0.27 \\
\hline
\end{tabular}

*S1 figures include sales of the Bluebird CC range and the replacement Doritos range.

\begin{tabular}{|l|r|r|r|r|}
\hline & Mean & $\begin{array}{l}\text { Std. } \\
\text { Dev. }\end{array}$ & \multicolumn{1}{|c|}{ t } & $\begin{array}{l}\text { 2- tailed } \\
\text { sig. }\end{array}$ \\
\hline $\begin{array}{l}\text { (S1) Avg. monthly sales } \\
\text { 9m } \\
\text { prior - 3m after }\end{array}$ & 0.44 & 4.15 & 2.14 & 0.03 \\
\hline $\begin{array}{l}\text { (S2) Avg. monthly sales } \\
\text { 9m } \\
\text { prior - 3m after }\end{array}$ & 1.26 & 10.44 & 2.43 & 0.02 \\
\hline $\begin{array}{l}\text { (S3) Avg. monthly sales } \\
\text { 9m } \\
\text { prior - 3m after }\end{array}$ & 0.28 & 4.00 & 1.41 & 0.16 \\
\hline
\end{tabular}


Table IV.

Paired samples statistics by sub-category, pre- versus post-discontinuation (cereal)

\begin{tabular}{|l|l|r|r|r|r|}
\hline \multicolumn{2}{|c|}{} & Mean & \multicolumn{1}{|c|}{ N } & Std. Dev. & $\begin{array}{c}\text { Std. Error } \\
\text { Mean }\end{array}$ \\
\hline \multirow{2}{*}{ S1* } & Avg. monthly sales 9m prior & 9.21 & 540 & 6.20 & 0.27 \\
\cline { 2 - 6 } & Avg. monthly sales 3m after & 7.32 & 540 & 7.07 & 0.30 \\
\hline \multirow{2}{*}{ S2 } & Avg. monthly sales 9m prior & 8.07 & 540 & 7.26 & 0.31 \\
\cline { 2 - 6 } & Avg. monthly sales 3m after & 8.46 & 540 & 8.97 & 0.39 \\
\hline \multirow{2}{*}{ S3 } & Avg. monthly sales 9m prior & 10.54 & 540 & 11.62 & 0.50 \\
\cline { 2 - 6 } & Avg. monthly sales 3m after & 9.73 & 540 & 11.92 & 0.51 \\
\hline
\end{tabular}

* S1 figures include sales of Kellogg's Cocoa Crispix and its replacement Coco Pops Chex.

\begin{tabular}{|l|l|r|r|r|r|}
\hline \multicolumn{2}{|c|}{} & Mean & $\begin{array}{c}\text { Std. } \\
\text { Dev. }\end{array}$ & t & $\begin{array}{l}\text { 2-tailed } \\
\text { sig. }\end{array}$ \\
\hline S1 & $\begin{array}{l}\text { Avg. monthly } \\
\text { sales prior - } \\
\text { Avg. monthly } \\
\text { sales after }\end{array}$ & 1.89 & 5.70 & 7.70 & 0.00 \\
\hline S2 & $\begin{array}{l}\text { Avg. monthly } \\
\text { sales prior - } \\
\text { Avg. monthly } \\
\text { sales after }\end{array}$ & -0.39 & 5.93 & -1.51 & 0.13 \\
\hline S3 & $\begin{array}{l}\text { Avg. monthly } \\
\text { sales prior - } \\
\text { Avg. monthly } \\
\text { sales after }\end{array}$ & 0.81 & 7.70 & 2.45 & 0.02 \\
\hline
\end{tabular}


Figure 1.

Discontinuation of a Brand: Catalysts, Events and Actions

All three studies examine permanent discontinuations by a manufacturer.

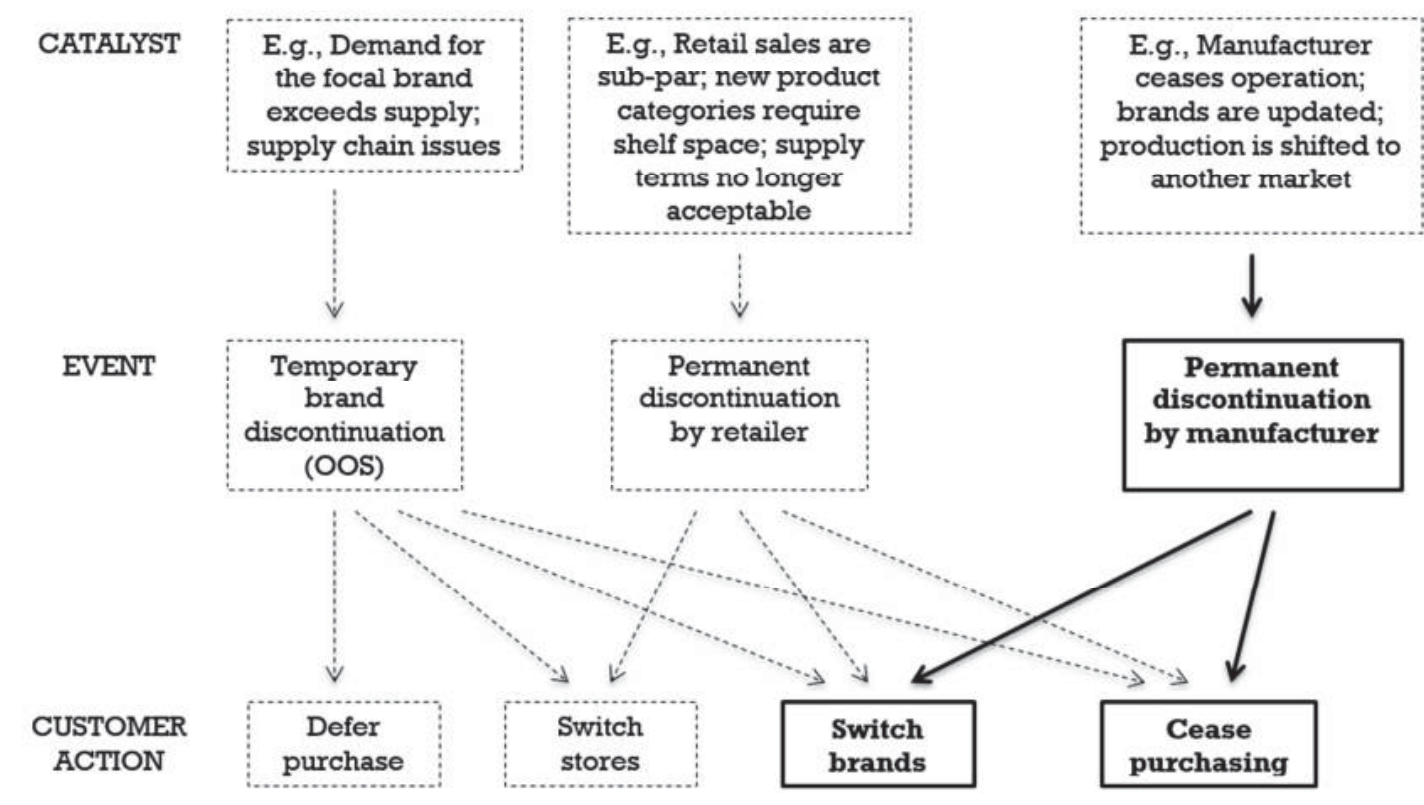


Figure 2.

The three studies, hypotheses and resultant actions assessed.

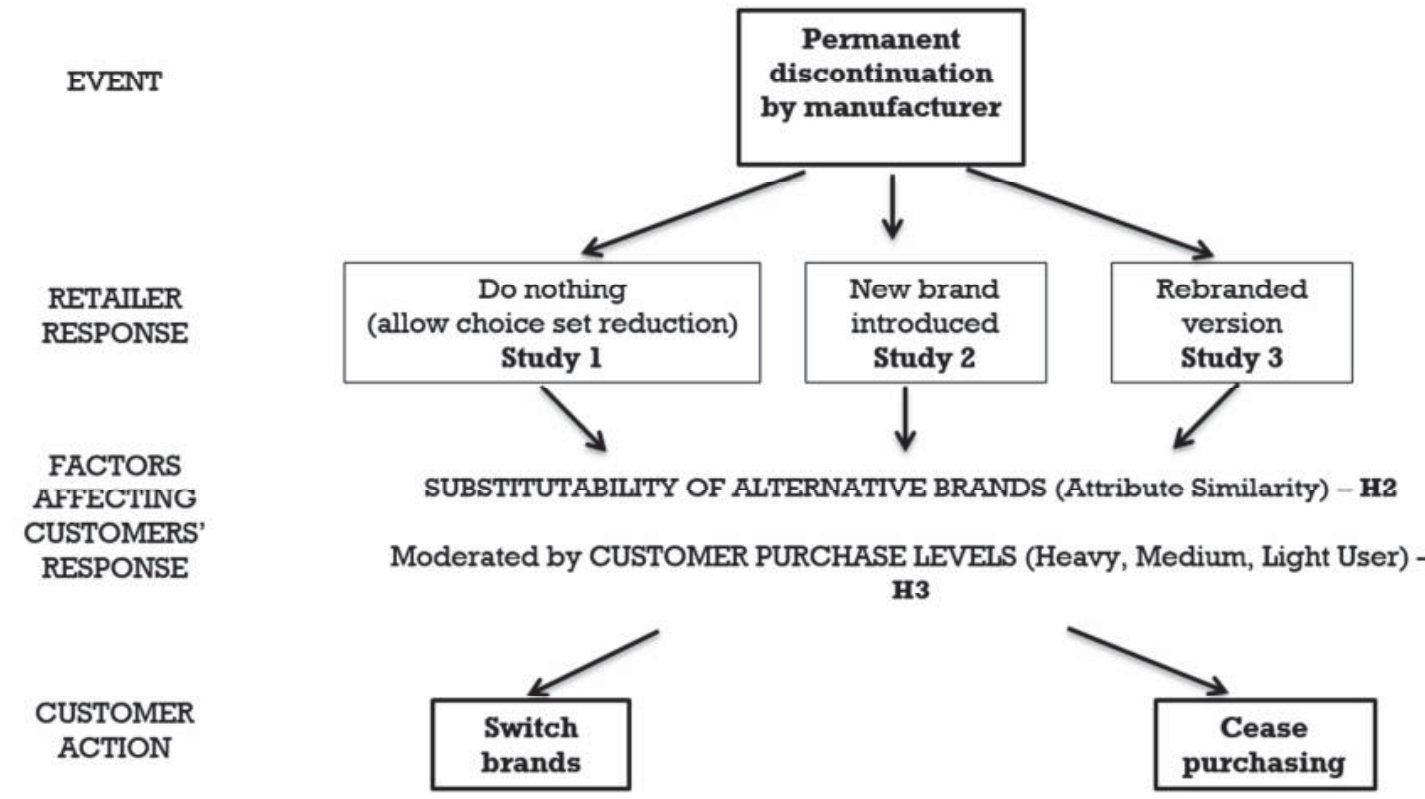


Figure 3.

Change in dollar spend due to discontinued Anlene milk brand across similarity categories by usage level. No replacement brand offered.

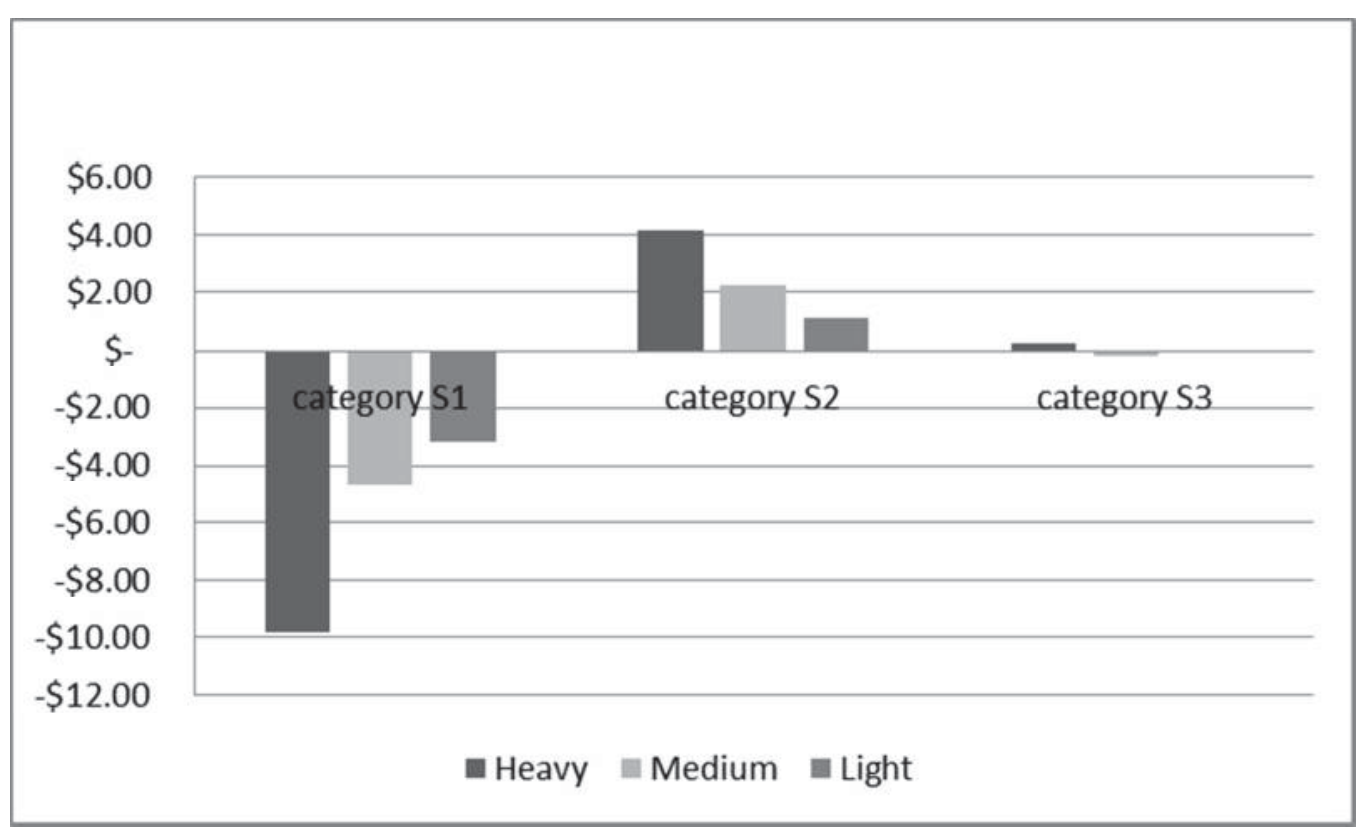


Figure 4.

Change in dollar spend due to replacement of Bluebird corn chip range with Doritos range across categories by usage level.

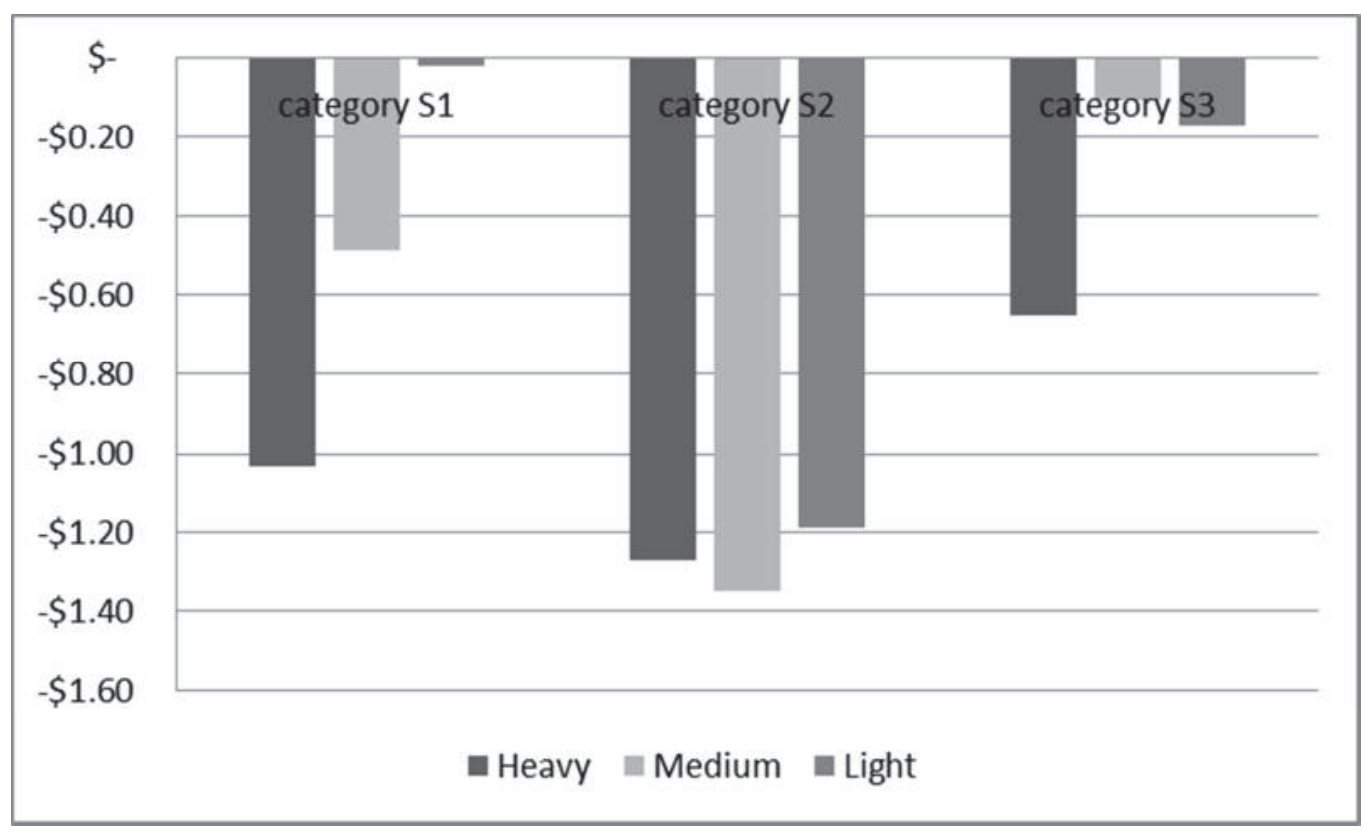


Figure 5.

Change in dollar spend due to rebranding of Kellogg's cereal across categories by usage level.

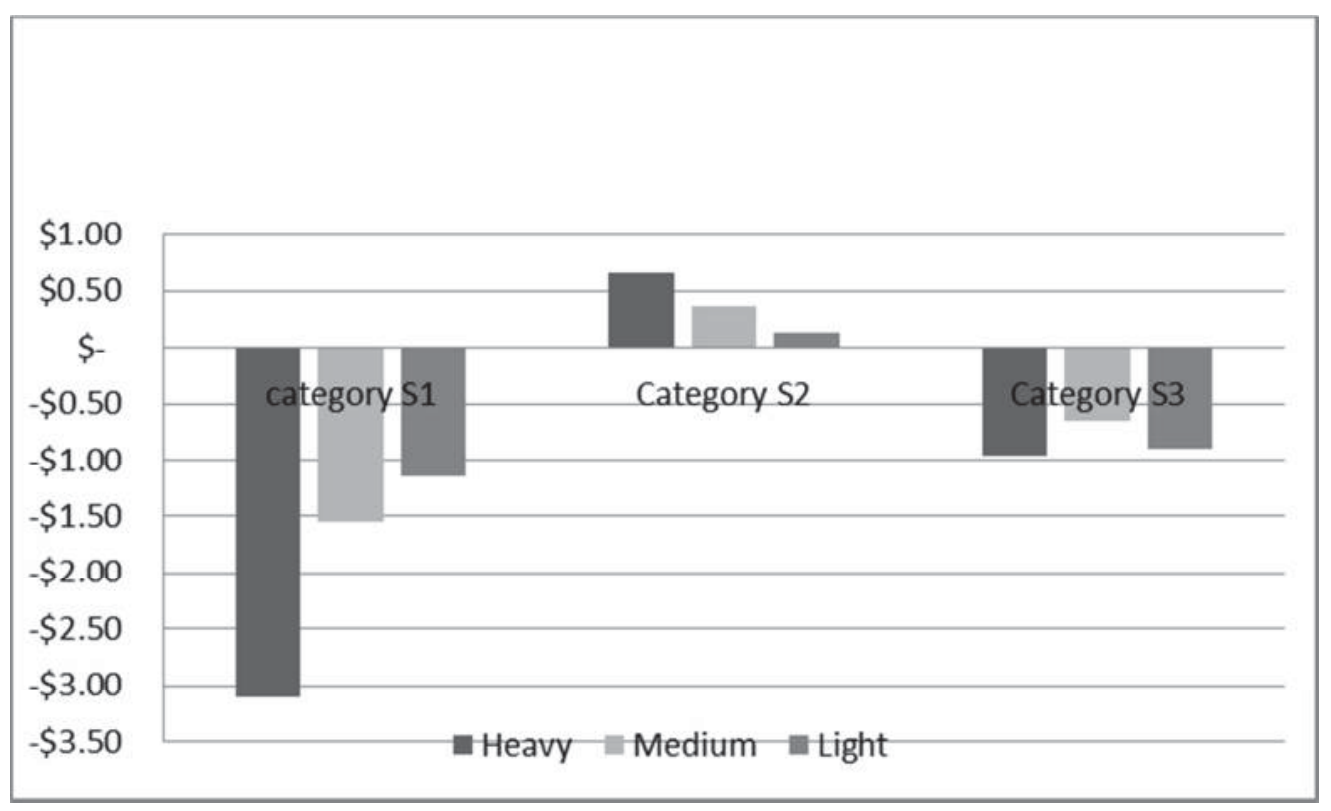

